Helena Gama ${ }^{1,11}$

Albertino Damasceno ${ }^{1,1,1,111}$

Carla Silva-Matos ${ }^{\mathrm{IV}}$

Domingos Diogo ${ }^{\prime \prime \prime}$

Ana Azevedo,

Nuno Lunet ${ }^{\prime, I I}$

\section{Low prevalence of hypertension with pharmacological treatments and associated factors}

Departamento de Epidemiologia Clínica. Medicina Preditiva e Saúde Pública. Faculdade de Medicina. Universidade do Porto. Porto, Portugal

Instituto de Saúde Pública da Universidade do Porto. Porto, Portugal

III Faculdade de Medicina. Universidade Eduardo Mondlane. Maputo, Moçambique

Iv Departamento de Doenças Não Transmissíveis. Ministério da Saúde de Moçambique. Maputo, Moçambique

\section{Correspondence:}

Nuno Lunet

Departamento de Epidemiologia Clínica.

Medicina Preditiva e Saúde Pública

Faculdade de Medicina do Porto

Al. Prof. Hernâni Monteiro

4200-319 Porto, Portugal

Email:nlunet@med.up.pt

\section{Baixa prevalência de hipertensão com tratamento farmacológico e fatores associados}

\begin{abstract}
OBJECTIVE: To assess the determinants of the lack of pharmacological treatment for hypertension.

METHODS: In 2005, 3,323 Mozambicans aged 25-64 years old were evaluated. Blood pressure, weight, height and smoking status were assessed following the Stepwise Approach to Chronic Disease Risk Factor Surveillance. Hypertensives (systolic blood pressure $\geq 140 \mathrm{mmHg}$ and/or diastolic blood pressure $\geq 90$ $\mathrm{mmHg}$ and/or antihypertensive drug therapy) were evaluated for awareness of their condition, pharmacological and non-pharmacological management, as well as use of herbal or traditional remedies. Prevalence ratios (PR) were calculated, adjusted for sociodemographic characteristics, cardiovascular risk factors and non-pharmacological treatment.
\end{abstract}

RESULTS: Most of the hypertensive subjects (92.3\%), and nearly half of those aware of their condition were not treated pharmacologically. Among the aware, the prevalence of untreated hypertension was higher in men $[\mathrm{PR}=1.61$; $95 \%$ confidence interval $(95 \% \mathrm{CI} 1.10 ; 2.36)]$ and was lower in subjects under non-pharmacological treatment $(\mathrm{PR}=0.58 ; 95 \% \mathrm{CI} 0.42 ; 0.79)$; there was no significant association with traditional treatments ( $\mathrm{PR}=0.75 ; 95 \% \mathrm{CI} 0.44 ; 1.26)$.

CONCLUSIONS: The lack of pharmacological treatment for hypertension was more frequent in men, and was not influenced by the presence of other cardiovascular risk factors; it could not be explained by the use of alternative treatments as herbal/traditional medicines or non-pharmacological management. It is important to understand the reasons behind the lack of management of diagnosed hypertension and to implement appropriate corrective actions to reduce the gap in the access to healthcare between developed and developing countries.

DESCRIPTORS: Hypertension, drug therapy. Antihypertensive Agents, therapeutic use. Medication Adherence. Patient Dropouts. Treatment Refusal. Complementary Therapies, utilization. 


\section{RESUMO}

OBJETIVO: Analisar os determinantes da falta de tratamento farmacológico da hipertensão.

MÉTODOS: Foram avaliados 3.323 moçambicanos de 25 a 64 anos em 2005. A pressão arterial, peso, altura e tabagismo foram avaliados segundo o estudo Stepwise Approach to Chronic Disease Risk Factor Surveillance. Os hipertensos (pressão arterial sistólica $\geq 140 \mathrm{mmHg}$ e/ou pressão arterial diastólica $\geq 90$ $\mathrm{mmHg}$ e/ou terapia anti-hipertensiva) foram avaliados para verificar se eram conscientes de sua hipertensão, se recebiam tratamento farmacológico ou não farmacológico e se usavam ervas ou remédios tradicionais. Foram calculadas as razões de prevalência $(\mathrm{PR})$ para hipertensão não tratada, ajustadas para características sociodemográficas, fatores de risco cardiovascular e tratamento não farmacológico.

RESULTADOS: A maioria dos hipertensos $(92,3 \%)$ e quase metade dos conscientes de sua hipertensão não eram tratados com fármacos. Entre os que sabiam ser hipertensos, a hipertensão sem tratamento era mais frequente em homens ( $\mathrm{PR}=1,61$; IC95\% 0,56;1,43) e não podia ser explicada pelo uso de tratamento não farmacológico $(\mathrm{PR}=0,58$; IC95\% 0,42;0,79); não havia associação significativa com os tratamentos tradicionais ( $\mathrm{PR}=0,75$; IC95\% $0,44 ; 1,26)$.

CONCLUSÕES: A falta de tratamento farmacológico da hipertensão, mais frequente em homens, não se explica por outros fatores de risco cardiovascular, nem pelo uso de tratamentos tradicionais ou tratamento não farmacológico. É importante entender as razões da falta de tratamento da hipertensão diagnosticada e implementar medidas corretivas apropriadas, para reduzir as diferenças no acesso a cuidados de saúde entre as populações dos países desenvolvidos e emergentes.

DESCRITORES: Hipertensão, quimioterapia. Anti-Hipertensivos, uso terapêutico. Adesão à Medicação. Pacientes Desistentes do Tratamento. Recusa do Paciente ao Tratamento. Terapias Complementares, utilização.

\section{INTRODUÇÃO}

Cardiovascular diseases are a growing public health challenge in low-income countries, namely in Sub-Saharan Africa. The increasing frequency of risk factors such as hypertension, obesity, diabetes or smoking and the ageing of the populations are key elements in the undergoing epidemiologic transition. ${ }^{20,25}$ Cardiovascular diseases are the leading cause of death worldwide, contributing to a third of all deaths, most of which in developing countries. ${ }^{2}$ A systematic review showed that there were no significant differences in the awareness, treatment and control of hypertension between developed and developing countries. ${ }^{17}$ Specifically in Mozambique, in 2007 the "diseases of the cardiovascular system" had a sizeable impact on the overall burden of death: approximately $15 \%$ of all deaths in subjects aged over 49 years. ${ }^{a}$ We have previously shown a high prevalence of hypertension, along with low awareness and pharmacological treatment. ${ }^{1}$

The awareness of hypertension and the presence of concomitant cardiovascular risk factors (age, sex, overweight/obesity, smoking) are important determinants of the treatment and control of hypertension. ${ }^{17}$ However, this has seldom been addressed in sub-Saharan Africa. The cultural specificities may contribute for the frequent use of traditional medicine, as well as the lack of financial resources, might have an impact on the management of hypertension in this region. ${ }^{17,20,26, \mathrm{~b}}$ The identification

a Loureiro J, Gaspar M, Levene V. Mortalidade em Moçambique - Inquérito nacional sobre causas de mortalidade, 2007/8. Moçambique: Instituto Nacional de Estatística; 2009.

b World Health Organization. Traditional Medicine. Geneva; 2008 [cited 2012 Jan 25]. [Fact sheet, 134]. Available from: http://www.who.int/ mediacentre/factsheets/fs134/en/\# 
of cost-effective solutions for the management of hypertension is a World Health Organization (WHO) priority. ${ }^{14,24}$ Understanding the determinants of non-pharmacologically treated hypertension in this setting may contribute to identifying locale-specific barriers to hypertension control, as well as population groups to be targeted by hypertension awareness-raising and control-promoting interventions. Therefore, we extended our previous analyses on the prevalence, awareness and treatment of hypertension in a representative sample of Mozambican adults. ${ }^{1}$ This study aimed to assess the determinants of lack of pharmacological treatment of hypertension. We considered the potential effect of traditional or non-pharmacological treatments, as well as the presence of other cardiovascular risk factors.

\section{METHODS}

This study was based on a national cross-sectional study conducted in Mozambique between September and November 2005. ${ }^{1}$ A representative sample of adults aged 25 to 64 years old was assembled through a complex multistage sampling procedure. Ninety-five geographical clusters were selected across the country; all the households from each cluster were listed and 25 randomly selected and visited.

The number of geographical clusters and the number of households per cluster were defined aiming to select approximately 2,800 participants, ensuring the sample representativeness at a national level and considering the expected number of eligible subjects per household according to the population estimates for the study period. ${ }^{c}$ There was no substitution of the households in which no one answered the door and the inquirers were instructed to make several attempts to contact members of the selected households at different times and on different days to minimize selection bias. All eligible subjects in the same household $(3,378)$ were invited to take part in this investigation. Fifty-five subjects refused and 3,323 participated in the study.

The participants were evaluated following the WHO STEPwise approach to chronic disease risk factor surveillance (STEPS), ${ }^{\mathrm{d}}$ using standardized methods. Trained interviewers conducted face-to-face interviews and physical measurements in each household, according to a Portuguese version of the WHO STEPS instrument for non-communicable disease risk factors (core and expanded version 2.1). ${ }^{\mathrm{d}}$

Blood pressure was measured on a single occasion by non-physician trained interviewers using a semiautomatic sphygmomanometer (OMRON $3^{\mathrm{TM}}$ ) with appropriate cuff size. After a 5-minute rest, blood pressure was measured twice, one minute apart, and a third measurement was performed if the difference between the first two was $>10 \mathrm{mmHg}$ for systolic or diastolic blood pressures. We used the mean of the two measurements or the mean of the last two when three measurements were done for analysis.

Arterial hypertension was defined as systolic blood pressure $\geq 140 \mathrm{mmHg}$ and/or diastolic blood pressure $\geq 90 \mathrm{mmHg}$ and/or taking antihypertensive drug therapy in the previous two weeks. Hypertensive subjects were classified as aware of their status when they reported having been told by a health professional in the previous 12 months that they had hypertension/ high blood pressure, or when reporting a pharmacological or non-pharmacological treatment for hypertension. Participants answering affirmatively to a close-ended question on the use of antihypertensive medication in the previous two weeks were classified as treated pharmacologically for hypertension.

Non-pharmacological management of hypertension was assessed by asking participants if they were advised to change diet, to do exercise, lose weight, or quit smoking due to hypertension, by indication of a health professional.

A close-ended question was used to assess the current use of any herbal or traditional remedy for the management of raised blood pressure.

Anthropometric measurements were obtained with the participants wearing light clothing and no footwear. Body weight was measured to the nearest $0.1 \mathrm{~kg}$ using a digital scale, and height to the nearest $0.1 \mathrm{~cm}$ in the standing position using a portable stadiometer. Body mass index (BMI) was calculated as weight $(\mathrm{kg})$ divided by squared height $\left(\mathrm{m}^{2}\right)$, and divided into the categories defined by the $\mathrm{WHO}^{24}<25.0 \mathrm{~kg} / \mathrm{m}^{2}, 25.0$ to $29.9 \mathrm{~kg} / \mathrm{m}^{2}$ and $\geq 30 \mathrm{~kg} / \mathrm{m}^{2}$.

Participants were classified as ever having smoked (current or previous smokers) and non-smokers.

The classification of the place of residence as urban (in any of the 23 cities and 68 towns) or rural (outside cities or towns), and the definition of categories for the highest level of education attained were done in accordance with the 1997 census.

We considered the 1,140 subjects classified as hypertensive (weighted prevalence: $33.1 \%$ ), of which 218 were aware of their condition (weighted prevalence: $15.1 \%$ among the hypertensive). The analyses were conducted considering the sampling weights and

\footnotetext{
c Cubula B. Metodologia de estimação para os resultados do inquérito de avaliação dos factores de risco para as doenças cardiovasculares, STEPS (OMS). Moçambique: Instituto Nacional de Estatística: 2005.

d World Health Organization. STEPS manual. World Health Organization; 2011 [cited 2011 Mar 29]. Available from: http://www.who.int/chp/ steps/manual/en/index.html
} 
adjusting for strata and clustering at primary sampling unit level using Stata, version 11.1.

The prevalence of untreated hypertension (among hypertensive subjects and those aware of their hypertension) was estimated with the corresponding $95 \%$ confidence intervals $(95 \% \mathrm{CI})$. The association between gender, education, place of residence, non-pharmacological treatment, use of herbal/traditional medicines and two major cardiovascular risk factors (overweight/obesity and smoking) and lack of treatment of hypertension was quantified through mutually adjusted prevalence ratios (PR) with $95 \% \mathrm{CI}$, computed using Poisson regression. ${ }^{12}$

The study protocol was approved by the National Mozambican Ethics Committee (Populacional study of risk factors of cardiovascular diseases, Mocambique, 2005) and written informed consent was obtained from all participants.

\section{RESULTS}

Women represented $53.9 \%$ of the sample, nearly half the participants were aged below 45 years old and $21.8 \%$ between 55 and 64 years old. Approximately $1 / 3$ had no formal education and the population was predominantly rural $(61.0 \%)$. The overall weighted prevalence of obesity and ever having smoked was $8.2 \%$ and $18.3 \%$, respectively. A higher percentage of women (67.6\%), $20.8 \%$ had no formal education and most subjects (64.7\%) lived in urban areas among the hypertensive subjects that were aware of their condition. Obesity was nearly twice as frequent in this group and smoking more than three times less prevalent (Table 1).

Most of the hypertensive subjects (92.3\%) and nearly half of the aware were not treated pharmacologically for their condition (Figure).

The results from a model including gender, education, place of residence, non-pharmacological treatment, use of herbal/traditional medicines, overweight/

Table 1. Characteristics of the study sample.

\begin{tabular}{|c|c|c|c|c|c|c|}
\hline \multirow[b]{2}{*}{ Variable } & \multicolumn{3}{|c|}{ Hypertensive subjects $(\mathrm{N}=1,140)$} & \multicolumn{3}{|c|}{$\begin{array}{l}\text { Hypertensive subjects aware of their } \\
\text { condition }(\mathrm{N}=218)\end{array}$} \\
\hline & $\mathrm{n}$ & Unweighted $(\%)^{\mathrm{a}}$ & Weighted $(\%)^{\mathrm{a}}$ & $\mathrm{n}$ & Unweighted $(\%)^{\mathrm{a}}$ & Weighted $(\%)^{a}$ \\
\hline \multicolumn{7}{|l|}{ Gender } \\
\hline Women & 636 & 55.8 & 53.9 & 153 & 70.2 & 67.6 \\
\hline Men & 504 & 44.2 & 46.1 & 65 & 29.8 & 32.4 \\
\hline \multicolumn{7}{|l|}{ Age (years) } \\
\hline 25 to 34 & 271 & 23.8 & 24.6 & 25 & 11.5 & 10.9 \\
\hline 35 to 44 & 303 & 26.6 & 26.2 & 60 & 27.5 & 29.9 \\
\hline 45 to 54 & 329 & 28.9 & 27.5 & 83 & 38.1 & 37.3 \\
\hline 55 to 64 & 237 & 20.8 & 21.8 & 50 & 22.9 & 21.9 \\
\hline \multicolumn{7}{|c|}{ Education (years) $)^{b}$} \\
\hline None & 342 & 30.1 & 34.4 & 42 & 19.4 & 20.8 \\
\hline 1 to 4 & 398 & 35.0 & 35.6 & 79 & 36.6 & 37.2 \\
\hline 5 & 161 & 14.2 & 13.1 & 31 & 14.4 & 18.4 \\
\hline 6 to 7 & 120 & 10.6 & 9.0 & 25 & 11.6 & 11.0 \\
\hline$\geq 8$ & 116 & 10.2 & 7.8 & 39 & 18.1 & 12.6 \\
\hline \multicolumn{7}{|c|}{ Place of residence } \\
\hline Rural & 489 & 42.9 & 61.0 & 53 & 24.3 & 35.3 \\
\hline Urban & 651 & 57.1 & 39.0 & 165 & 75.7 & 64.7 \\
\hline \multicolumn{7}{|c|}{ Body mass index $(\mathrm{kg} / \mathrm{m} 2)^{\mathrm{b}}$} \\
\hline$<25.0$ & 785 & 69.8 & 74.0 & 103 & 48.1 & 45.8 \\
\hline 25.0 to- 29.9 & 207 & 18.4 & 17.8 & 63 & 29.4 & 37.5 \\
\hline$\geq 30.0$ & 133 & 11.8 & 8.2 & 48 & 22.4 & 16.6 \\
\hline \multicolumn{7}{|l|}{ Ever smoked } \\
\hline No & 955 & 83.8 & 81.7 & 204 & 93.6 & 94.8 \\
\hline Yes & 185 & 16.2 & 18.3 & 14 & 6.4 & 5.2 \\
\hline
\end{tabular}

a Within each variable the sum of the proportions may not be $100 \%$ due to rounding off.

${ }^{b}$ The sum of the number of participants in each category may be lower than the total because of missing data. 


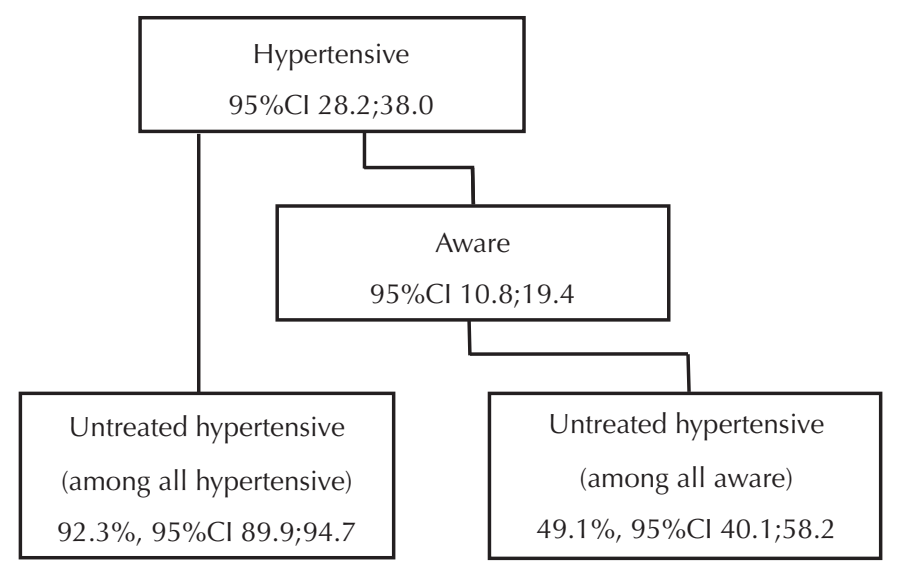

Figure. Prevalence, awareness and untreated hypertension (among all hypertensive and among those aware of their hypertensive status) in the population aged 25 to 64 years old in Mozambique.

obesity and smoking showed that lack of pharmacological treatment for hypertension was significantly more frequent among men (adjusted PR $=1.05,95 \% \mathrm{CI}$ $1.01 ; 1.09)$ and less frequent among the subjects under non-pharmacological (adjusted PR $=0.46,95 \% \mathrm{CI}$ $0.36 ; 0.59$ ) or traditional (adjusted $\mathrm{PR}=0.68,95 \% \mathrm{CI}$ $0.47 ; 1.00)$ treatments. Among the hypertensive subjects aware of their condition, being male was more strongly associated with lack of pharmacological treatment (adjusted $\mathrm{PR}=1.61 ; 95 \% \mathrm{CI} 0.56 ; 1.43$ ) and the inverse relation between non-pharmacological and pharmacological treatments remained statistically significant (adjusted $\mathrm{PR}=0.58 ; 95 \%$ CI $0.42 ; 0.79$ ). No other sociodemographic characteristics (age, education, place of residence) or cardiovascular risk factors (obesity, smoking) could explain the high prevalence of untreated hypertension in the population (Table 2).

\section{DISCUSSION}

The high prevalence of untreated hypertension observed in Mozambique is largely explained by the lack of diagnosis, since $15 \%$ of the hypertensive subjects were aware of their condition. Half of the diagnosed hypertensives were receiving pharmacological treatment for hypertension. Among the aware, under treatment with anti-hypertensive drugs was more frequent among men. Neither the use of herbal/traditional medicines nor the preference for non-pharmacological management of hypertension could explain the lack of treatment in this population.

The less frequent treatment of hypertension among men is in accordance with previous observations in other populations., ${ }^{411,17}$ This could be attributed to the fact that women have contact with healthcare systems more frequently due to maternal and child health programs and tend to use more medication in general. ${ }^{8}$ Our hypothesis is that the gender differences were more pronounced among the aware due to a lower adherence to, or persistence of, the pharmacological treatment among men. The evaluation of the differences in adherence and compliance to treatment between genders in this population would allow us to test this hypothesis and strengthen our study. The antihypertensive drugs most commonly used in this setting, central acting methyldopa and reserpine, are associated with severe side effects, mainly among men. ${ }^{19}$ Diuretics and beta blockers are used less frequently, especially in the rural regions, and are also associated with erectile dysfunction. ${ }^{19}$ Angiotensin-converting enzyme inhibitors are not affordable for this region of limited resources, and these are not easily accessible through the public sector, in addition to the fact that they are less effective in the black hypertensive population. ${ }^{10}$

The presence of risk factors for cardiovascular diseases could account for an increased awareness of the overall cardiovascular risk and to a higher frequency of treatment of hypertension. ${ }^{19}$ The distribution of many cardiovascular risk factors and the awareness of illnesses are dependent on sociodemographic characteristics, namely in Mozambique. .,9,21 $^{2}$

Although in other epidemiological studies blood pressure levels among current smokers were similar or lower than those observed in non-smokers, ${ }^{6}$ the former tend to use health care systems less often and to have unhealthier habits which may account for our results. ${ }^{16}$ Unlike those observed in our study, overweight and obese subjects are more likely to be aware of their hypertension, although it is less likely to be controlled because a more aggressive treatment is needed to overcome their higher peripheral resistance and attain control of the hypertension. ${ }^{7,18,23}$

Due to the scarcity of resources in this setting, we expect a frequent use of non-pharmacological or traditional treatments, especially among hypertensive 
Table 2. Prevalence ratio of untreated hypertension among the hypertensive population and among those aware of their hypertensive status.

\begin{tabular}{|c|c|c|c|c|}
\hline \multirow{3}{*}{ Variable } & \multicolumn{4}{|c|}{ Untreated hypertension (pharmacologically) } \\
\hline & \multicolumn{2}{|c|}{ Among the hypertensive } & \multicolumn{2}{|c|}{$\begin{array}{c}\text { Among the aware of their } \\
\text { hypertensive status }\end{array}$} \\
\hline & $\%$ & $\begin{array}{l}\text { Prevalence ratio } \\
\qquad(95 \% \mathrm{Cl})^{\mathrm{a}}\end{array}$ & $\%$ & $\begin{array}{c}\text { Prevalence ratio } \\
(95 \% \mathrm{Cl})^{\mathrm{a}}\end{array}$ \\
\hline \multicolumn{5}{|l|}{ Gender } \\
\hline Women & 88.8 & 1 & 40.7 & 1 \\
\hline Men & 96.5 & $1.05(1.01 ; 1.09)$ & 66.7 & $1.61(1.10 ; 2.36)$ \\
\hline \multicolumn{5}{|l|}{ Age (years) } \\
\hline 25 to 44 & 94.1 & \multirow{2}{*}{$11.00(0.97 ; 1.03)$} & 51.7 & 1 \\
\hline 45 to 64 & 90.4 & & 47.3 & $1.10(0.79 ; 1.52)$ \\
\hline \multicolumn{5}{|c|}{ Education (years) } \\
\hline 0 to 4 & 93.4 & 1 & 46.9 & 1 \\
\hline 5 to 7 & 91.0 & $1.03(0.99 ; 1.07)$ & 54.7 & $1.29(0.94 ; 1.77)$ \\
\hline$\geq 8$ & 87.8 & $1.01(0.96 ; 1.07)$ & 49.8 & $1.11(0.76 ; 1.62)$ \\
\hline \multicolumn{5}{|c|}{ Place of residence } \\
\hline Rural & 96.0 & 1 & 53.9 & 1 \\
\hline Urban & 86.6 & $0.97(0.92 ; 1.02)$ & 46.5 & $0.90(0.56 ; 1.43)$ \\
\hline \multicolumn{5}{|c|}{ Body mass index $(\mathrm{kg} / \mathrm{m} 2)$} \\
\hline$<25.0$ & 95.2 & 1 & 48.2 & 1 \\
\hline 25.0 to 29.9 & 86.0 & $1.02(0.96 ; 1.09)$ & 55.9 & $1.18(0.76 ; 1.83)$ \\
\hline$\geq 30$ & 82.8 & $1.01(0.94 ; 1.07)$ & 43.3 & $1.08(0.66 ; 1.75)$ \\
\hline \multicolumn{5}{|l|}{ Ever smoked } \\
\hline No & 90.8 & 1 & 47.8 & 1 \\
\hline Yes & 98.9 & $1.01(0.99 ; 1.03)$ & 73.6 & $1.24(0.83 ; 1.84)$ \\
\hline \multicolumn{5}{|c|}{ Non-pharmacological treatment } \\
\hline No & 98.4 & 1 & 65.3 & 1 \\
\hline Yes & 42.9 & $0.46(0.36 ; 0.59)$ & 42.9 & $0.58(0.42 ; 0.79)$ \\
\hline \multicolumn{5}{|c|}{ Use of herbal/traditional medicines } \\
\hline No & 93.0 & 1 & 49.7 & 1 \\
\hline Yes & 43.6 & $0.68(0.47 ; 1.00)$ & 43.6 & $0.75(0.44 ; 1.26)$ \\
\hline
\end{tabular}

a Prevalence ratios are adjusted for all the variables presented in the table.

subjects not receiving pharmacological treatment. In other resource poor settings, the use of complementary and alternative medicines was observed in up to $30 \%$ of the hypertensive population. ${ }^{11,13,15}$ In our study, the non-pharmacological approaches to the management of hypertension and the use of herbal/traditional remedies were observed mainly among those also treated pharmacologically. A large proportion of the hypertensive subjects are not receiving any support for the management of hypertension, even among the aware of their condition.

The trend towards urbanization, population ageing and acquisition of obesogenic lifestyles observed in low income countries ${ }^{14}$ contributes to an increasing burden of chronic diseases in these settings. This requires preventive measures, namely through reducing excessive salt intake, ${ }^{3}$ but provision of equal access to appropriate management of medical conditions, such as hypertension, is needed. Supplying the primary healthcare units with basic equipment such as a calibrated and functioning sphygmomanometer may contribute to a higher proportion of the population having their blood pressure measured ${ }^{3}$ and a consequent improvement in the awareness of hypertension. Ensuring that essential drugs for the effective treatment of hypertension are made available, through a continuous supply of medicine with appropriate quality control and at affordable prices, ${ }^{3}$ is expected to result in a higher proportion of treated hypertensives, as well as in better adherence to the treatments. Both the health-care workers and the general population need to be aware of the importance of an asymptomatic disease such as hypertension, ${ }^{3}$ and awareness raising campaigns may contribute to 
this. The continuous monitoring of the management is necessary and future health surveys conducted in Mozambique should allow the assessment of the determinants of awareness and treatment of hypertension, considered within a basis of management of the global cardiovascular risk. ${ }^{24}$

This study provides valuable information to understand unmet needs in the management of hypertension in this setting, but some limitations need to be discussed.

The measurement of blood pressure on a single occasion contributes to an overestimation of blood pressure and prevalence of hypertension and to an underestimation of awareness. ${ }^{18}$ Participants were considered aware of their status if they had been told in the previous year that they were hypertensive, which contributes to underestimating the life prevalence of awareness. However, this does not compromise the estimates of treatment among the aware.

Regarding pharmacological treatment, its assessment considering the use of antihypertensive medication in the previous two weeks contributes to an underestimation of treatment prevalence, by reflecting essentially the persistence of treatment. This explains the lower prevalence in the present study in comparison with other reports defining treatment as a previous prescription of anti-hypertensive drugs, regardless of current use. The prevalence of treatment was below the average of developed and developing

\section{REFERENCES}

1. Damasceno A, Azevedo A, Silva-Matos C, Prista A, Diogo D, Lunet N. Hypertension prevalence, awareness, treatment, and control in mozambique: urban/rural gap during epidemiological transition. Hypertension. 2009;54(1):77-83. DOI: http://dx.doi. org/10.11681/HYPERTENSIONAHA.109.132423

2. Fuster V, Voute J, Hunn M, Smith Jr SC. Low priority of cardiovascular and chronic diseases on the global health agenda: a cause for concern. Circulation. 2007;116(17):1966-70. DOI: http://dx.doi. org/10.1161/CIRCULATIONAHA.107.733444

3. Ibrahim MM, Damasceno A. Hypertension in developing countries. Lancet. 2012;380(9841):6119. DOI: http://dx.doi.org/10.1016/S01406736(12)60861-7

4. Jenson A, Omar AL, Omar MA, Rishad AS, Khoshnood K. Assessment of hypertension control in a district of Mombasa, Kenya. Glob Public Health. 2010;6(3):293306. DOI: http://dx.doi.org/10.1080/17441692.2010. 510478

5. Kamadjeu RM, Edwards R, Atanga JS, Unwin N, Kiawi EC, Mbanya JC. Prevalence, awareness and management of hypertension in Cameroon: findings of the 2003 Cameroon Burden of Diabetes countries worldwide, but it was higher than in other African studies relying on the STEPS methodology. ${ }^{7,5,17,22}$ According to the STEPS protocol, the use of antihypertensive medication was assessed without specifying the drugs that have a blood pressure lowering effect and other classes of drugs (e.g., anxiolytics) which may have been considered antihypertensive by the participants, contributing to an overestimation of the use of antihypertensive therapy.

Sample size limitations precluded the computation of robust sex- and place of residence-stratified estimates, which would contribute to a deeper understanding of the determinants of untreated hypertension. However, smoking habits and obesity were not associated with pharmacological treatment in this population, despite being two important and easy to measure risk factors that could be expected to influence the awareness of hypertension or the decision to treat it pharmacologically. ${ }^{2}$

In conclusion, the lack of pharmacological treatment of hypertension was more frequent in men, was not influenced by other cardiovascular risk factors, and could not be explained by the use of alternative treatments as herbal/traditional medicines or non-pharmacological management. The sub-treatment of hypertension is a major public health issue in Mozambique and the setting up of hypertension control programs may contribute to sizable improvements in the health status of the population.
Baseline Survey. J Hum Hypertens. 2006;20(1):91-2. DOI: http://dx.doi.org/10.1038/sj.jhh.1001936

6. Lee DH, Ha MH, Kim JR, Jacobs Jr DR. Effects of smoking cessation on changes in blood pressure and incidence of hypertension: a 4-year followup study. Hypertension. 2001;37(2):194-8. DOI: http://dx.doi.org/10.1161/01.HYP.37.2.194

7. Longo-Mbenza B, Ngoma DV, Nahimana D, Mayuku DM, Fuele SM, Ekwanzala F, et al. Screen detection and the WHO stepwise approach to the prevalence and risk factors of arterial hypertension in Kinshasa. Eur J Cardiovasc Prev Rehabil. 2008;15(5):503-8. DOI: http://dx.doi.org/10.1097/HJR.0b013e3282f21640

8. Lucas R, Lunet N, Carvalho R, Langa J, Muanantatha $M$, Nkunda LP, et al. Patterns in the use of medicines by university students in Maputo, Mozambique. Cad Saude Publica. 2007;23(12):2845-52. DOI: http:// dx.doi.org/10.1590/S0102-311X2007001200005

9. Lunet N, Araujo C, Silva-Matos C, Damasceno A, Gouveia L, Azevedo A. Changing patterns of tobacco consumption in Mozambique: evidence from a migrant study. BMC Public Health. 2011;11(1):322. DOI: http://dx.doi.org/10.1186/1471-2458-11-322

10. ALLHAT Officers and Coordinators for the ALLHAT Collaborative Research Group. The Antihypertensive 
and Lipid-Lowering Treatment to Prevent Heart Attack Trial. Major outcomes in high-risk hypertensive patients randomized to angiotensinconverting enzyme inhibitor or calcium channel blocker vs diuretic: The Antihypertensive and Lipid-Lowering Treatment to Prevent Heart Attack Trial (ALLHAT). JAMA. 2002;288(23):2981-97. DOI: http://dx.doi.org/10.1001/jama.288.23.2981

11. Mathenge W, Foster A, Kuper H. Urbanization, ethnicity and cardiovascular risk in a population in transition in Nakuru, Kenya: a populationbased survey. BMC Public Health. 2010;10:569. DOI: http://dx.doi.org/10.1186/1471-2458-10-569

12. McNutt LA, Wu C, Xue X, Hafner JP. Estimating the relative risk in cohort studies and clinical trials of common outcomes. Am J Epidemiol.2003;157(10):940-3. DOI: http://dx.doi.org/10.1093/aje/kwg074

13. Olisa NS, Oyelola FT. Evaluation of use of herbal medicines among ambulatory hypertensive patients attending a secondary health care facility in Nigeria. Int J Pharm Pract. 2009;17(2):101-5. DOI: http://dx.doi.org/10.1211/ijpp.17.02.0005

14. Opie LH, Mayosi BM. Cardiovascular disease in subSaharan Africa. Circulation. 2005;112(23):3536-40. DOI: http://dx.doi.org/10.1161/ CIRCULATIONAHA.105.597765

15. Osamor PE, Owumi BE. Complementary and alternative medicine in the management of hypertension in an urban Nigerian community. BMC Complement Altern Med. 2010;10:36. DOI: http://dx.doi.org/10.1186/1472-6882-10-36

16. Padrao P, Silva-Matos C, Damasceno A, Lunet N. Association between tobacco consumption and alcohol, vegetable and fruit intake across urban and rural areas in Mozambique. J Epidemiol Community Health. 2011;65(5):445-53. DOI: http://dx.doi. org/10.1136/jech.2009.099440

17. Pereira M, Lunet N, Azevedo A, Barros H. Differences in prevalence, awareness, treatment and control of hypertension between developing and developed countries. J Hypertens. 2009;27(5):963-75. DOI: http://dx.doi.org/10.1097/HJH.0b013e3283282f65
18. Pereira M, Azevedo A, Barros H. Determinants of awareness, treatment and control of hypertension in a Portuguese population. Rev Port Cardiol. 2011;29(12):1779-92.

19. Reffelmann T, Kloner RA. Sexual function in hypertensive patients receiving treatment. Vasc Health Risk Manag. 2006;2(4):447-55. DOI: http://dx.doi. org/10.2147/vhrm.2006.2.4.447

20. Samb B, Desai N, Nishtar S, Mendis S, Bekedam H, Wright $A$, et al. Prevention and management of chronic disease: a litmus test for health-systems strengthening in low-income and middle-income countries. Lancet. 2010;376(9754):1785-97. DOI:http://dx.doi. org/10.1016/S0140-6736(10)61353-0

21. Silva-Matos C, Gomes A, Azevedo A, Damasceno A, Prista A, Lunet N. Diabetes in Mozambique: Prevalence, management and healthcare challenges. Diabetes Metab. 2010;37(3):237-44. DOI: http:// dx.doi.org/10.1016/j.diabet.2010.10.006

22. Usman A, Mebrahtu G, Mufunda J, Nyarang'o P, Hagos $\mathrm{G}$, Kosia A, et al. Prevalence of non-communicable disease risk factors in Eritrea. Ethn Dis.2006;16(2):542-6

23. Wofford MR, Smith G, Minor DS. The treatment of hypertension in obese patients. Curr Hypertens Rep. 2008;10(2):143-50.

24. World Health Organization. Hypertension control. Report of a WHO Expert Committee. World Health Organ Tech Rep Ser 1996; 862:1-83.

25. Yusuf S, Reddy S, Ounpuu S, Anand S. Global burden of cardiovascular diseases: part I: general considerations, the epidemiologic transition, risk factors, and impact of urbanization. Circulation. 2001;104(22):2746-53. DOI: http://dx.doi. org/10.1161/hc4601.099487

26. Yusuf S, Reddy S, Ounpuu S, Anand S. Global burden of cardiovascular diseases: Part II: variations in cardiovascular disease by specific ethnic groups and geographic regions and prevention strategies. Circulation. 2001;104(23):2855-64. DOI: http://dx.doi. org/10.1161/hc4701.099488

The authors declare that there are no conflicts of interests. 